\title{
Zonas fronteiriças: \\ as imbricações derivadas da nova relação de visibilidade nas videografias de si
}

\author{
Bruno Costa
}

\section{Resumo:}

No atual regime de visibilidade, as diferenciações entre público e privado são combalidas, problematizadas e a morada da contemporaneidade não tem mais um muro que divide o espaço do público do privado. O íntimo pode agora ser exibido mundialmente principalmente por meio da internet, como nas videografias de si. Contudo, essa auto-inserção não é destituída de opacidade e apesar de produzirem um efeito de real, as pequenas janelas não exibem completamente os indivíduos que decidem mostrar-se, problematizando assim também o tropos de não-ficcionalidade do autobiográfico.

\section{Palavras Chave:}

Público, íntimo, privado, autobiografia, ficção.

\section{Abstract:}

At the actual visibility regime, the difference between public and private is weakened, problematized and contemporarity doesn 't have a division between public and private. The intimate can be shown worldwide mainly through internet, like a self videography. Although, this self insertion is not displaced of opacity and despite producing a real effect, the little windows don`t exhibit completely the individual who decides to show up , problematizing the non fiction between lines of self - biography.

\section{Keywords:}

Public, intimate, private, self-biography, fiction.

\section{Videografias de si}

As videografias de si do YouTube são pequenos vídeos autobiográficos que podem ser considerados como bons exemplos da nova relação da contemporaneidade entre público, íntimo e privado. Nelas, a escrita dos indivíduos navega entre uma notação biográfica, uma exposição pública e até uma exploração do íntimo a partir de práticas típicas do entretenimento. Estes pequenos vídeos são práticas que também revelam como o material para a constituição dos exercícios autobiográficos tem um caráter costumeiro e ordinário e a narração de si não precisa mais de eventos impactantes, o indivíduo contemporâneo busca sentido para a sua vida nos eventos mais corriqueiros do cotidiano. Mais do que isso, a biografia como um todo teleológico parece ser substituída pela narrativa do fragmento, do efêmero e do corriqueiro, há uma despretensão à totalidade e até mesmo a recusa ao teleológico como o modo mais eficaz ou verdadeiro de explicação. Essa opção pelo fragmento busca no presente a explicação para o presente. A narração historicizante das autobiografias tradicionais em que o presente surge como a consequiência de várias ações passadas passa a ser desacreditada. Como consequiência, já não é mais o extraordinário o que define a individualidade de cada um, não é a singularidade absoluta dos destinos individuais a 
constituidora do senso de um "eu". Para selves conectados entre si e integrados pelo sistema midiático, a busca pelo senso de individualidade está mais próxima da exposição de características que fazem ressaltar as semelhanças que cada um dos indivíduos tem com os outros.

A opção pelo costumeiro e cotidiano busca aproximar os indivíduos já devidamente resignados em relação à sua solidão, que abandonaram a interioridade reflexiva como forma de constituição do self e pela interação com os outros buscam um ponto de contato para exprimir sua subjetividade. Abre-se mão da exploração dos pormenores das peculiaridades de cada um, da escrutinação profunda de si mesmo em favor da comunicabilidade das práticas cotidianas que permitem uma descoberta de si que é também uma descoberta dos outros. Isso não constitui, de modo algum, um declínio da interioridade ou uma perda da subjetividade. É mais uma opção pelos aspectos mais comunicáveis da individualidade, que ressalta antes os pontos em comum presentes na criação do sentido de "eu" dos indivíduos. Portanto, nas práticas videográficas selecionadas, o foco de análise não é a perda de profundidade, mas antes uma conformação midiática das histórias de vida. Os pequenos eventos do cotidiano são o material de muito dos vídeos, mas o ordinário adquire novas cores quando descrito nos vídeos. Essa midiatização dos eventos empresta aos vídeos características dos subsistemas dos meios de comunicação, seja da publicidade, do entretenimento ou do jornalismo. Uma questão do dia-a-dia, uma dúvida ou uma opinião, são revestidas de maior importância quando registradas e exibidas. Ao mesmo tempo, apesar do forte acento midiático, esses produtos se filiam a uma tradição autobiográfica, resistem a categorização de ficcionais e usam o bios como material de composição com o objetivo de acionar um efeito de real.

\section{Público, íntimo e privado}

A contemporaneidade pode ser definida também como um cenário tipicamente midiático, no qual conceitos como público e privado se embaçam graças à mediação do aparato midiático. Se há, como afirma Sodré (2002), a emergência de um quarto bios que medeia as relações e encena uma nova doxa (significando tanto opinião como celebridade) capaz de ajudar na constituição da identidade a partir de uma troca social, pode-se declarar que uma das conseqüências é a alteração nas relações entre o público e o privado. Além de determinar uma nova moralidade em consonância com a ordem do consumo, a mídia determina uma nova eticidade, ou seja, cria e referenda outras práticas e ações sociais (Sodré destaca a produção contínua de um atual midiático e a reiteração de uma familiaridade). Portanto, a negociação com o ethos tradicional envolve essencialmente o lugar dos sujeitos, agora aproximados pelo ambiente midiático, levando a uma confusão entre espaços.

O processo de constituição de uma esfera pública na modernidade foi também uma realocação destes espaços, mas eles pareciam manter ao menos características específicas que permitiam sua diferenciação. Assim, o debate sobre a interpenetração entre o público, o privado e íntimo deve se calcar em bases mais sólidas que no mero declínio da esfera pública. Mesmo na concepção habermesiana, a esfera pública burguesa é muito mais um modelo ideal do que uma condição fundadora das sociabilidades e da vida política. Na verdade, a organização da esfera pública deste tipo foi em si uma espécie de reconstituição do modelo grego de polis.

Para os gregos, a vida pública - o bios politikos - era uma espécie de evolução da condição humana e por isso, "ser político significava atingir a mais alta possibilidade da existência humana." (ARENDT, 2001: 74). Por outro lado, a falta de um espaço privado (caso dos escravos) significava deixar de ser humano. Nesses termos, compreende-se melhor a afirmação aristotélica de que ser humano é ser político, ou seja, a humanidade plena só é atingida quando o homem deixa a esfera do privado e adquire uma segunda vida pública.

Para o ser político, o que garante sua admissão na esfera pública é a propriedade, ou seja, ser 
propriamente dono de algo. Como alerta Hannah Arendt (2001), a moderna confusão entre propriedade e riqueza é um desvio da significação original de ambos. Na antiguidade, a propriedade era a garantidora da condição privada do cidadão, pré-requisito a todos que aspiravam uma vida pública. Por isso, o confisco da propriedade era um ato eminentemente político. Sem a sua propriedade, o cidadão perdia a "propriedade" necessária para ser um homem público, para ser até um ser humano plenamente. Afastado do público e sem o privado, ele jamais poderia atingir a condição humana.

Já na recriação de uma nova vida pública nas sociedades modernas européias do século XVIII, a relação entre público e privado é acrescida com a inclusão da intimidade. Esta inclusão muda a relação, pois agora o individuo tem um lugar para estabelecer a sua subjetividade. A manifestação literária desta nova expressão social são as cartas e "não é por acaso que o século XVIII se torna um século de cartas: escrevendo cartas, o indivíduo desenvolve-se em sua subjetividade." (HABERMAS, 1984: 65). É equívoco, porém, crer que esta subjetividade é alheia ao público. Se não há uma publicização do íntimo, há certamente uma indiscrição. Segundo expressão corrente da época, uma maneira elogiosa de tratar das cartas era defini-las como "boas para serem impressas". Esta intimidade, expressão da subjetividade consagrada na carta, só pôde surgir com uma mudança no privado. Esta mudança pode ser percebida inclusive na arquitetura das residências burguesas, com a valorização dos espaços privados, como os quartos, em detrimento dos espaços públicos, como os grandes salões. O homem valoriza o íntimo dentro do privado como forma de emancipação da individualidade.

É este espaço privado garantidor da individualidade do ser humano que se perde com a ascensão da sociedade midiatizada. O refúgio do lar já não garante resguardo perante o mundo exterior, na verdade, o mundo exterior já penetrou tão fortemente no espaço privado que tal refúgio torna-se impensável. As mídias, neste contexto, são justamente aquelas que publicizam esse espaço privado e aqui podemos retomar a conotação de mídia como um meio que se interpõe entre dois objetos de uma relação. Como todo processo de mediação prevê uma adequação, uma adaptação mútua, pode-se dizer que uma das causas e consequiências da confusão entre público e privado é a midiatização de ambos. No encontro midiático do público com o privado eles perdem sua condição ontológica essencial, sua propriedade. $\mathrm{Na}$ contemporaneidade, com o alargamento das possibilidades e práticas de mediação, essa confusão é ainda maior, a tal ponto que chega a ser difícil delimitar algum espaço exclusivo para qualquer um dos dois. $\mathrm{O}$ público invade e é invadido pelo privado, que, por sua vez, não é de modo algum privado, e sim público.

De todo modo, a plena separação entre público e privado é sempre utópica. Como esferas interdependentes, eles provêm uma distância, mas conservam uma profunda relação, pois o privado necessita de projetar-se para existir, e esta projeção se dá por meio da publicização. Todo privado traz a reboque uma potência de publicização, ou seja, conforma-se em consonância com o público, ainda que não venha a ser como tal, pois o ser-em-si não tem qualquer realidade, as forças da vida íntima "vivem uma espécie de existência incerta e obscura, a não ser que, e até que, sejam transformadas, desprivatizadas e desindividualizadas, por assim dizer, de modo a se tornarem adequadas à aparição pública." (ARENDT, 2001: 60-61). Em ambientes híbridos, tal qual a internet, a publicização do privado vai um pouco mais além. Mesmo que a internet não seja, strictu sensu, um espaço público, todo conteúdo disponibilizado para acesso global tem uma potencialidade de publicidade em si, que não necessariamente se realiza (devido, entre outros fatores, ao excesso de conteúdo disponível), mas que ajuda a determinar o privado, o prepara para ser publicizado.

Na modernidade, a consolidação do íntimo trouxe um novo elemento para a equação. O declínio da esfera pública, da vida pública como tal, trouxe o íntimo para o espaço público. A grande problemática desta realocação é que o íntimo é avesso a muita publicidade, quando tornado público à exaustão, ele corre o risco de expressar não a individualidade, mas a indistinção. Decerto, o íntimo precisa de alguma publicidade para conformar-se, pois a garantia da pre-sença do homem (Dasein) se dá no processo de ser- 
com. Na concepção heideggeriana, a constituição ontológica do homem se dá no ser-aí (1), na pre-sença, o modo de afirmação do ser como tal. Ao preferir o termo pre-sença (Dasein) à existência, Heidegger quer evitar a concepção de uma essência humana, conceito que, na melhor das hipóteses, poderia falar de algo que é comum a todos os homens (a afecção da alma aristotélica), mas que jamais poderia definir a determinação do homem como ser e indivíduo.

O conceito de pre-sença (Dasein) garante ao homem uma existência como ser com outros seres, sem que haja uma exclusão dos outros. Os outros, pelo contrário, são aqueles que garantem a individualidade. Contra certo pressuposto que toma como válido um sujeito em si dado a priori, distante dos outros sujeitos e dos objetos, Heidegger (2002b) prefere uma relação de constituição mútua. O sujeito simplesmente dado é no máximo um truque de retórica, uma ênfase em uma parte de uma relação entre sujeito e objeto que desconsidera o próprio caráter da relação ao opor, criar uma distância, entre dois entes circumconformadores, uma ênfase em um ponto de uma relação que é essencialmente circular. Por conseguinte, ainda que o conceito de (Dasein) garanta um existir próprio de cada ser, é na co-presença (Dasein with others) que a pre-sença é determinada existencialmente.

A falta e a "ausência" são modos da co-presença apenas possíveis porque a pre-sença, enquanto ser-com, permite o encontro de muitos em seu mundo. Ser-com é sempre uma determinação da própria pre-sença; ser co-presente caracteriza a pre-sença de outros na medida em que, pelo mundo da pre-sença, libera-se a possibilidade para um ser-com. A própria pre-sença só é na medida em que possui a estrutura essencial do ser-com, enquanto co-pre-sença que vem ao encontro de outros. (HEIDEGGER, 2002b: 171-172).

Assim, o outro já está, de algum modo, subsumido na pre-sença, é uma assunção dada a priori. Todavia, se íntimo, público e privado existem em uma relação, ou seja, se eles se conformam sempre em relação um ao outro, isso não pressupõe uma sinonímia e nem uma indistinção. Na relação entre público e privado, a existência de cada um dos dois como conceitos diversos e até opostos ajuda a constituir cada um deles. O público deriva do privado, mas só pode existir enquanto o privado for propriamente privado, ou ainda, se o privado tiver uma propriedade. Com a publicização do privado, o público tende a desaparecer como tal e o novo privado apresentado na esfera pública não é essencialmente privado, muito menos íntimo. A publicização dá ao privado uma impessoalidade própria dos processos da publicidade que, como a define Heidegger, é o modo de ser do impessoal.

Outro fator componente da impessoalidade nas mediações contemporâneas é o entretenimento; os produtos culturais midiáticos tentam de algum modo recriar uma familiaridade com os indivíduos. $\mathrm{O}$ engajamento nas narrativas do entretenimento é possível graças a um processo de identificação do observador (a audiência) com o destino dos personagens (nos filmes e programas televisivos), com a apresentação de histórias de vida (sempre buscando uma universalidade) de modo a possibilitar uma autoinserção no mundo representado. Há de se considerar, entretanto, que este processo de auto-inserção permite uma identificação a partir das generalidades, tipos e estereótipos. Os indivíduos devidamente treinados para serem observadores conseguem participar do entretenimento resguardando sua pessoalidade, pois ele joga com conhecimentos já familiares - assim ele reforça as posições prévias - e permite ao mesmo tempo uma simulação de experiências de vida, sem compromisso ou o custo das mesmas. (LUHMANN, 2005).

As videografias de si trazem as estratégias do entretenimento para a grafia de si, revelam a auto-exposição deliberada de indivíduos de acordo com alguns ditames orientadores do entretenimento. Uma das primeiras questões que surgem em relação a este aspecto é a autenticidade de relatos que navegam entre a escrutinação de si e o entretenimento, entre o público e o privado. Afinal, não há como clamar espontaneidade em vídeos, não é possível saber quantas vezes aquelas falas foram repetidas, quantas 
vezes os gestos foram encenados. Isso, porém, não é suficiente para delimitar a esfera do fingimento.

De todo modo, a relação entre o fingir e o autêntico é sempre complexa porque a ficção deve, de alguma maneira, fingir a realidade para projetar o imaginário. Como destaca Wolfgang Iser, os modos de enunciação do ficcional se dão pelos atos de fingir. "Como o texto ficcional contém elementos do real, sem que se esgote na descrição deste real, então seu componente fictício não tem o caráter de uma finalidade em si mesma, mas é, enquanto fingida, a preparação de um imaginário.” (ISER, 2002: 955).

Segundo o autor, esse processo se dá por meio de três atos: a seleção, a combinação e o desnudamento da ficcionalidade. O processo de seleção se guia por um pressuposto, ele se alimenta do que escolheu deixar para trás. O mundo apresentado em um texto - aqui tomado em sentido lato - afirma sua existência justamente por aquilo que foi deixado de lado. Ao mostrar os limites daquilo que foi selecionado, o ato de seleção revela também a temática do texto, ele permite apreender a intencionalidade do mesmo.

$\mathrm{O}$ ato seguinte, o da combinação, permite ao texto ficcional, entre outras coisas, criar relações características da ficcionalidade, compor campos simbólicos através de estratégias textuais que são aceitáveis porque se trata de uma ficção. O arranjo de elementos díspares é pertinente, o uso da linguagem para a criação de efeitos estéticos e a subversão das regras lexicais são formas de combinação a serviço da ficcionalidade. E embora, a princípio, o termo léxico seja de exclusiva aplicação ao uso das palavras, pode-se considerar que o mesmo processo se dê em narrativas visuais, ainda que não exista uma unidade formadora mínima como a palavra.

Esses dois atos confluem para o terceiro e mais importante, o desnudamento da ficcionalidade. E é exatamente neste ponto que as videografias de si se mostram como híbridos, pois o texto ficcional deve revelar sua despretensão ao real, mostrar que não se qualifica como realidade. Ao invés, ele propõe um "como se", nos convida e nos pede que o entendamos como se fosse real. No caso dos vídeos analisados, esse desnudamento não é explícito, pelo menos, não aparentemente. Eles se anunciam como autobiográficos, clamam seu parentesco com a realidade. Porém, se formos considerar o ambiente em que estão localizados, ou seja, um site como YouTube esse desnudamento talvez exista.

Afinal, o YouTube não se ancora, como o discurso jornalístico, no real. É um espaço para difusão de vídeos, um espaço marcadamente de entretenimento, mas que também não permite uma imersão completa, a experiência de se assistir um vídeo em uma pequena janela relembra aos usuários que há uma grande dose de mediação. Vários discursos se sobrepõem, textos e imagens. São milhares de vídeos hospedados, organizados por assunto e por popularidade, algo como uma videolocadora virtual. Nessa videolocadora, porém, não há uma seção autobiográfica, não existe definição de gêneros a partir dos níveis de ficcionalidade.

Portanto, pode-se ponderar que o ato autobiográfico destes vídeos tenha um pé fincado na ficção, que eles estejam em uma zona fronteiriça e esta posição seja uma estratégia para se alcançar os efeitos tanto da realidade quanto do ficcional, usando as propriedades específicas do meio onde se encontram. Desse modo, o desnudamento da ficcionalidade seria a revelação de que aquilo, embora calcado no real, é também ficção. O jogo proposto seria então explorar essas zonas fronteiriças, o anônimo se travestindo de midiático, o real sob a capa do entretenimento e o ficcional com cara de realidade.

\section{Efeito de real nas videografias de si}

Nas videografias de si, o efeito de real faz parte de um arsenal que atua em favor da autenticidade das manifestações autobiográficas, ao mesmo tempo em que revela uma estratégia estética, ele ajuda na constituição de um estilo específico. À primeira vista, este estilo seria uma espécie de realismo, no qual o 
real é solicitado para dar verossimilhança às narrativas e isso pode ser percebido na escolha do conteúdo, que usa o autobiográfico como a base para a sua constituição. De certo modo, a autobiografia nega e foge da ficção para tentar estabelecer-se em um patamar diferente e hierarquicamente superior em relação ao ficcional quando se trata de realidade. Isso, porém, não passa de uma estratégia enunciativa que considera que a realidade primária repousa "no mundo lá fora", desconsiderando os processos cognitivos de formação de mundo. (LUHMANN, 2005). Esta estratégia age na direção de criar uma ilusão, é como se os textos não-ficcionais pudessem entrar em contato com essa realidade primária externa e, portanto, serem mais "reais" do que os textos ficcionais, sempre restritos ao seu próprio universo. Ao mesmo tempo, esta vida "real" aparece colorida de tons midiáticos, graças ao modo que esse conteúdo é apresentado.

Nas práticas videográficas, o efeito de real é conseguido através da conjunção de vários elementos, atravessando todo o processo de feitura dos mesmos. Por um lado, a câmera digital para uso doméstico gera uma imagem de pouca perfeição técnica e, ao assim proceder, afasta das videografias a parecença com as imagens técnicas de alta qualidade que são a tônica dos produtos ficcionais do sistema midiático. Entre os vídeos selecionados, porém, destacam-se "Still Around" e "Telling all at 58", no qual a qualidade da imagem é surpreendentemente boa. Nesse caso, há uma inversão na relação, o doméstico imitando o massivo, o que só reforça a percepção de que, em uma era de confluência midiática, a especificidade de cada meio tende a desaparecer. Assim, aquilo que poderia ser denominado de uma estética videográfica doméstica (a imagem granulada, enquadramentos mal feitos, edição precária) já foi incorporada e é usada como recurso, por exemplo, no cinema quando este busca um efeito de domesticidade, a precariedade típica dos produtos amadores já foi absorvida e é emulada para dar às narrativas ficcionais ares de realidade.

Em relação a este aspecto pode-se fazer uma diferenciação entre o efeito de real conseguido pelas condições de produção - caso das videografias de si - e a tentativa de obter esse efeito através de uma opção estilística - caso dos produtos ficcionais. Os produtos ficcionais optam por um estilo dentre muitos, escolhem este tipo de representação. Nas videografias, este estilo se tornou dominante por causa das contingências da produção - a maioria das câmeras domésticas efetivamente possui pouca definição. Porém, o entrecruzamento das fronteiras entre o midiático e o não-midiático torna essa diferenciação problemática. Uma vez que a precariedade fingida foi adotada no cinema como estratégia para conferir autenticidade, familiaridade ou domesticidade - e esse uso foi absorvido pelos indivíduos que produzem suas videografias - o efeito de real acionado não pode ser considerado simplesmente como uma conseqüência das restrições técnicas.

As restrições técnicas podem ser observadas no posicionamento da câmera, sua posição fixa em frente ao autor-personagem e nos cortes, raros e perceptíveis. Do outro lado da câmera, geralmente percebe-se um cenário doméstico que remete à pessoalidade dos quartos ou à familiaridade dos ambientes de trabalho. Aparentemente, há pouco esmero na produção, seja no figurino ou na maquiagem. Ao mesmo tempo, não se pode pressupor que os elementos de cena estejam todos casualmente posicionados. Nos vídeo "Still Around" e "(FAQ) questions and rumors" há elementos cênicos que parecem estar cuidadosamente alocados para criar um efeito de real. No primeiro, a correspondência fechada que repousa sobre a mesa, o urso de pelúcia e a caricatura pendurada na parede ao fundo parecem não ter nenhuma função. No segundo, o violão ao fundo também não diz nada sobre a narrativa ou o personagem. De acordo com Barthes (1988), parte da estratégia da prosa realista era a descrição supérflua de objetos que não tinham qualquer função na narrativa a não ser clamar certa realidade, objetos que não dizem nada além de "nós somos reais". A notação do insignificante é uma maneira de anular o caráter de representatividade dos objetos, de apresentar a verossimilhança como realidade. Em alguns vídeos o cenário cumpre essa função, apresenta-se como o pano de fundo, como uma imagem vista através de uma janela transparente da 
realidade.

Já o vídeo "Sorrow"traz imagens impactantes de uma garota chorando e o discurso verbal, desta vez, é substituído pela trilha sonora, a música "Everybody hurts" do grupo americano REM. Justaposta à imagem, esta trilha consegue criar uma situação de imersão, abre o caminho para a simpatia. Ao mesmo tempo, trabalha contra o efeito de real, é uma mediação marcante que faz lembrar o trabalho de edição, ou seja, faz lembrar que o choro foi primeiro gravado e só depois foi adicionada a música. Assim, a autora confia na verossimilhança do seu ato, na ação de chorar perante a câmera para garantir a autenticidade do seu vídeo. Em outro vídeo sem fala, no qual a tarefa de delimitar parcialmente o sentido é também confiada à música, chamado "How do u get that lonely" o uso da trilha sonora, pelo contrário, acentua o efeito de real. Esta diferença nos efeitos causados ocorre porque a trilha sonora, que também dá nome ao vídeo, não foi adicionada depois da gravação. No momento em que foi gravado o vídeo, a autora ouvia esta música em seu computador e, para aumentar o efeito de real, ela ainda cantarola a canção. Na verdade, este é todo o conteúdo do vídeo, uma música de fundo e a autora cantando despreocupadamente, sem nenhum corte ou trabalho de edição.

Nestes dois vídeos, há elementos que permitem delimitar algumas marcas de expressão dos indivíduos na contemporaneidade, a cultura pop e seus artefatos funcionando como elementos mediadores para a expressão da subjetividade. Isso ocorre porque, em parte, os indivíduos constroem suas identidades através de referências a produtos culturais: músicas, filmes, livros e celebridades. De acordo com Luhmann (2005), o pressuposto necessário para a emergência do entretenimento como um modo de agenciamento da realidade são indivíduos que já não formam sua identidade de acordo com sua origem. Assim, quando em contato com as narrativas ficcionais do entretenimento, eles podem se identificar com a história apresentada sem que necessitem de vivenciá-la. O uso de depoimentos, histórias de vida - como no caso das videografias de si - só reforça esta janela de identificação que permite aos indivíduos experimentarem por um momento as liberdades cognitivas sem qualquer perda de realidade, o entretenimento possibilita a auto-inserção no mundo representado. As videografias seriam uma duplicação do modo de engajamento proposto pelas narrativas do entretenimento, uma expressão da reprodução do sistema cognitivo dos meios de comunicação. "É mais realista pressupor que certos princípios seguidos na definição do que deve ou não ser impresso ou transmitido são passados adiante para o público; e são na verdade esses princípios que definem o que deverá aparecer como informação." (LUHMANN, 1990: 96, tradução nossa) (2). Essa duplicação dos critérios de diferenciação é um modo de compreender a relação dos meios de comunicação com os indivíduos. Para Bauman (2008: 90), esse tipo de duplicação seria uma socialização bem sucedida, na qual está expresso um desejo dos indivíduos de realizar o "que é necessário para capacitar o sistema a se auto-reproduzir."

A edição do vídeo "Gullible is not in the Dictionary" sugere uma réplica da linguagem dos videoclipes. A sucessão de cortes por todo o vídeo é uma marca de mediação importante, um exemplo que o efeito de real nas videografias não depende de uma apresentação que esconde a mediação. $O$ uso de uma estrutura narrativa similar àquela do videoclipe mostra como a apresentação do real através da construção de uma segunda realidade - plasmada e fragmentada - já prestou provas suficientes de consistência e, então, pode ser tomada como autêntica. Se existe algo como um realismo nas videografias de si, ele é, de certo modo, oposto ao realismo histórico em relação ao aspecto narrativo, ao invés da descrição pormenorizada que mascarava os processos de ficcionalização com intuito de acionar o efeito de real, persiste nas videografias a subjetividade assumida do depoimento e a mediação aparente. (JAGUARIBE, 2007). A autora compartilha, através do vídeo, sua preocupação com a rápida aceitação de informações, com a falta de questionamento das pessoas sobre aquilo que elas ouvem. A palavra "gullible", presente no título, significa exatamente isso, é um adjetivo usado para caracterizar as pessoas que aceitam sem questionar aquilo que lhes é dito. Neste vídeo, como em alguns outros, percebe-se certa consciência em relação aos possíveis efeitos causados, algum domínio das técnicas audiovisuais e uma percepção quantos aos 
possíveis usos do site.

Essas características são especialmente distinguíveis no vídeo "Dear YouTube...WTF-----!", no qual a autora, uma veterana na comunidade (segundo suas próprias palavras) reclama de algumas mudanças na interface e no layout do site. Como no vídeo anterior, o ancoramento no real está concentrado no conteúdo do discurso verbal, um discurso sobre algo que deveria interessar ou, ao menos, estaria relacionado a todos os que participam do site. Contudo, esta estratégia concorre mais para a criação de outro efeito, ajudando a constituir um conjunto de qualidades que marcam esse e outros vídeos como típicos do YouTube, no qual o caráter autobiográfico adquire especificidades relacionados ao ambiente e ao suporte. $\mathrm{O}$ ambiente em que estão alocados os vídeos, um site, não permite a imersão completa e o suporte videográfico valoriza a performance, a atuação para a câmera. Assim, estes vídeos autobiográficos ajudam a definir um modo autobiográfico específico do site, no qual a mediação é visível, a presença do outro é solicitada e o próprio meio é lembrado.

Outros vídeos que também ajudam a definir um modo autobiográfico típico são "(FAQ) questions and rumors", "500.000+ views" e "Please interpret my dream". Os dois primeiros são produzidos por pessoas com alta participação no site, que já produziram, além destes, muitos outros vídeos e que sempre levam em conta a presença da audiência. Para evidenciar essa característica, basta conferir o número de acessos aos vídeos, as duas autoras têm sua própria audiência de milhares de outros participantes. No primeiro vídeo, a autora revela detalhes de sua vida videográfica no site, mostra como são feitos os seus vídeos, expõe seus equipamentos de produção e os processos de edição. Além disto, ela faz uma longa explanação para dirimir quaisquer dúvidas sobre sua identidade, sua idade, sua nacionalidade. Este é um vídeo de alto teor metalinguístico, é um vídeo sobre os vídeos do YouTube, sobre o processo de fazer vídeos para esta comunidade e sobre os processos interacionais envolvidos, produzido por uma pessoa que tem bastante consciência das possibilidades interacionais das videografias de si.

O vídeo "500.000 views" é outro em que sobressaem as características específicas dos vídeos do YouTube . É um vídeo celebrativo, no qual a autora comemora o fato de seus vídeos terem sido assistidos 500.000 vezes. Esses números expressam o quanto ela está integrada na comunidade, e como, de alguma forma, ela descobriu como tornar populares suas pequenas autobiografias em vídeo. Esses dois vídeos definem uma espécie de realismo específico do YouTube, um realismo de certa forma com característica diferentes dos outros realismos, no qual assume-se uma vida mediada e a consciência da mediação não é necessariamente escondida ou disfarçada, pelo contrário, muitas vezes ela é lembrada e incentivada através de vídeos que a destacam. Há, também, uma constante chamada para a interação. Nesse contexto, mediar-se pela câmera não torna menos autêntica a experiência e nem mais fraca a interação. A interação pelos vídeos é muitas vezes um complemento das interações face a face e outras vezes só ela parece capaz de dar sentido aos pequenos eventos do cotidiano.

Esse é o caso do vídeo "Please interpret my dream", que não existe sem a assunção a priori de um outro, de alguém para dialogar. A chamada para o diálogo em forma de pedido de interpretação de um sonho, a forma clara com que o sonho é relatado e a aparente sinceridade com que a mulher de meia idade faz esse pedido concorrem para determinar uma característica do modo autobiográfico específico das videografias de si, seu caráter dialógico. O fato de ela se filmar no banheiro, a justificativa para essa decisão - por causa da iluminação - criam o efeito de real, e, mais uma vez, a precariedade da produção atua em favor da autenticidade e da verossimilhança.

O vídeo "Still Around", produzido por um senhor de idade, aposta no conteúdo autobiográfico para conseguir convencer a audiência de que tudo revelado efetivamente aconteceu. É um vídeo com maior duração que a maioria, cerca de oito minutos, em que são relatadas algumas das vivências do autor no mundo musical. São apresentadas pessoas que efetivamente existem e situações que verdadeiramente 
aconteceram. Esse confiança no poder realista dos fatos é ainda mais marcante em outro vídeo. Em "The story of my eating disorder", o autobiográfico se torna ainda mais patente, já que nele a autora conta com detalhes as várias etapas de sua doença, a anorexia. $O$ assunto por si já afasta grande parte da desconfiança sobre a ficcionalidade do vídeo, e a descrição pormenorizada da doença, dos sintomas, do diagnóstico e da relação da autora com seus familiares durante todo o processo torna esse vídeo um depoimento em que o realismo é conseguido pela extrema riqueza de detalhes da descrição, pela montagem que enfatiza os vários aspectos (diagnóstico, a doença, as conseqüências) e pelo próprio tema, uma doença grave que atinge várias jovens da mesma idade. Contar a história em vídeo, compartilhá-la através do site, torna ainda mais crível toda a descrição da autora-personagem.

Se no vídeo anterior, a força do discurso verbal, o conteúdo, eram os suportes mais fortes sobre a qual as imagens da própria autora-personagem em frente à câmera se apoiavam, no vídeo "My boyfriend sucks" não existe uma primazia de qualquer um dos pontos. O discurso verbal, uma longa reclamação sobre o suposto namorado da autora-personagem, é acompanhado pelas imagens do mesmo, que embora esteja no fundo da cena, aparece constantemente. O singular deste vídeo é sua evolução, ele começa com a câmera apontada para a autora e com a mesma reclamando sobre os defeitos de seu parceiro. Enquanto ocorre este depoimento, o namorado aparece, ao fundo, em outro computador. Começa então um diálogo entre os dois, entrecortado por comentários para a câmera da autora, o diálogo vai se tornando mais ríspido e vira uma discussão e o vídeo subitamente termina. O inusitado deste acontecimento é com certeza o que mais garante um efeito de real; já a ação paralela ao depoimento reforça o conteúdo do discurso verbal e o fim abrupto ajuda a consolidar o efeito de autenticidade do vídeo.

Nas videografias de si, o efeito de real assume algumas características específicas relacionadas aos modos de produção, aos modos de exibição e à presença da câmera. Em cada uma delas, estes aspectos ganham maior ou menor força, embora somente na confluência dos três possa-se conformar algo como realismo típico, que é tanto uma conseqüência das condições da produção, como um estilo derivado do realismo midiático da televisão e do cinema aplicado a um material de forte caráter autobiográfico. $\mathrm{O}$ efeito de real serve a diversos fins, objetiva angariar simpatia, promover a interação ou simplesmente dar verossimilhança àquilo que é contado.

A pouca perfeição técnica e o pouco domínio das técnicas cinematográficas acionam o efeito de domesticidade e autenticidade necessários que, combinados ao uso das histórias de vida - o viés autobiográfico - acionam um particular efeito de real. Em alguns casos, confia-se mais na imagem como portadora da mensagem, mas na maioria dos casos ela funciona apenas como acessória para o discurso verbal. Percebe-se também uma variação do nível de consciência sobre os efeitos possivelmente causados pelos vídeos e também uma conseqüente tentativa de alcançá-los. Mas, de modo geral, o efeito de real se manifesta mais fortemente quando há pouco trabalho de edição e pouco esforço para consegui-lo.

\section{Bibliografia:}

ARENDT, Hannah. A condição humana. 10a edição. Rio de Janeiro: Forense Universitária, 2001.

ARENDT, Hannah. A vida do espírito: o pensar, o querer, o julgar. $3^{\text {a }}$ edição. Rio de Janeiro: Relume Dumará, 1995.

BAUMAN, Zigmund. Vida para o consumo. Rio de Janeiro: Jorge Zahar, 2008.

BOURDIEU, Pierre. A ilusão biográfica. In: Ferreira, M. e Amado J. (orgs.). Usos e abusos da história 
oral. Porto Alegre, Fundação Getúlio Vargas, 1998.

BARTHES, Roland. O rumor da língua. São Paulo: Brasiliense, 1988.

HABERMAS,Jurgen. Mudança estrutural da esfera pública. Rio de Janeiro: Tempo Brasileiro,1984

HEIDEGGER, Martin. Ser e tempo. 12ª edição. Petrópolis: Vozes, 2002.

ISER, Wolgang. Os atos de fingir ou o que é fictício no texto ficcional. In: LIMA, Luiz Costa. Teoria da literatura em suas fontes. 3a. ed. Rio de Janeiro: Civilização Brasileira, 2002. 2v.

JAGUARIBE, Beatriz. O choque do real: estética, mídia e cultura. São Paulo: Rocco, 2007.

LEJEUNE, Plhilipe. O pacto autobiográfico y otros estudios. Madri: Megazul-Endymion, 1994.

LUHMANN, Niklas. A realidade dos meios de comunicação. São Paulo: Paulus, 2005.

LUHMAN, Niklas. Essays on self-reference. New York: Columbia University Press, 1990.

RENOV, Michael. The subject of documentary. Minneapolis: University of Minnesota Press, 2004.

SODRÉ, Muniz. Antropológica do espelho: uma teoria da comunicação linear e em rede. Petrópolis: Vozes, 2002.

\section{Vídeos}

(FAQ) Questions and rumors . Disponível em . Acesso em 28 out. 2008.

500,000 + views. Disponível em . Acesso em 28 out. 2008.

Depression. Disponível em < http://br.youtube.com/watch?v=I5En1iMs2L0>. Acesso em 28 out. 2008

Gullible is not in the dictionary. Disponível em . Acesso em 28 out. 2008.

How do u get that lonely. Disponível em . Acesso em 28 out. 2008.

My boyfriend sucks. Disponível em . Acesso em 26 de nov. 2004.

Please interpret my dream. Disponível em . Acesso em 26 nov. 2008.

Still Around. Disponível em . Acesso em 28 out. 2008.

The story of my eating disorder. Disponível em . Acesso em 26 nov. 2008.

Why is so hard to accept that we are just normal? Disponível em . Acesso em 26 nov. 2008. 


\section{Notas:}

(1) Umas das traduções mais correntes para do termo Dasein nas línguas latinas e também a mais literal (o termo da é uma preposição que denota movimento e sein significa “ser").

(2) "It is more realistic to assume that certain principles followed in determining whether something should be printed or broadcast are passed on to the public; and it is in fact such principles that define what shall appear as information".

\section{Mini Currículo :}

Bruno Costa é doutorando em Comunicação pela Pontifícia Universidade Católica do Rio Grande do Sul 